\title{
Selfies no Tinder: masculinidades hegemônicas como performance
}

Selfies in Tinder: hegemonic masculinities as performance

Selfies en Tinder: masculinidades hegemónicas como performance

Flora ARDENGHI DUTRA

Universidade Federal de Santa Maria, Brasil / floradutra@hotmail.com

Carlos ORELLANA

Universidade Federal de Santa Maria, Brasil / lapisazul2984@gmail.com

Chasqui. Revista Latinoamericana de Comunicación

N.o ${ }^{\circ}$ 135, agosto - noviembre 2017 (Sección Monográfico, pp. 143-158)

ISSN 1390-1079 / e-ISSN 1390-924X

Ecuador: CIESPAL

Recibido: 20-05-2017 / Aprobado: 31-08-2017 


\title{
Resumo
}

O artigo explora como os selfies promovem masculinidades hegemônicas no ciberespaço apresentadas no aplicativo mais popular de relacionamento do mundo, o Tinder, e como estes homens se relacionam com o smartphone para gerir performances masculinas a partir da imagem de si. Procura-se compreender como o gênero e as subjetividades constroem o self pelo habitus compartilhado entre homens e como estas identidades podem ser percebidas pela imagem na construção de um perfil num aplicativo de dispositivo móvel. Através de uma etnografia multissituada foram analisados dez perfis desde agosto de 2015 até março de 2017. O estudo é uma contribuição para o campo das masculinidades e das identidades de gênero atravessadas pela rede online.

Palavras-chave: selfies; masculinidades; smartphones; performance.

\begin{abstract}
The article explores how the selfies promote hegemonic masculinities in cyberspace presented in the most popular relationship application around the world, Tinder, and how these men relate to the smartphone to manage male performances from self-image. It seeks to comprehend how gender and subjectivities build the self by the habitus shared among men and how these identities can be perceived by the image in the construction of a profile in a mobile device application. Through a multisite ethnography, ten profiles were analyzed from August 2015 to March 2017. The study is a contribution to the field of masculinities and gender identities crossed by the online network.
\end{abstract}

Keywords: selfies; masculinities; smartphones; performance.

\section{Resumen}

El artículo explora cómo las selfies promueven masculinidades hegemónicas en el ciberespacio presentadas en la aplicación más popular de relacionamiento del mundo, el Tinder, y cómo estos hombres se relacionan con el smartphone para gestionar performances masculinas a partir de la imagen de sí. Se busca comprender cómo el género y las subjetividades construyen el self por el habitus compartido entre hombres y cómo estas identidades pueden ser percibidas por la imagen en la construcción de un perfil en una aplicación móvil. A través de una etnografía multisituada se analizaron diez perfiles desde agosto de 2015 hasta el marzo de 2017. El estudio es una contribución al campo de las masculinidades y de las identidades de género atravesadas por la red online.

Palabras clave: selfies; masculinidades; smartphones; performance. 


\section{Introdução}

O aplicativo Tinder foi criado por estudantes da Universidade da Califórnia em 2012 com o objetivo de unir pessoas com mútuo interesse. $\mathrm{O}$ aplicativo se tornou tão importante para encontros e namoros que os homens revelam levarem no bolso o smartphone para checar se houve ou não novas combinações a cada hora. O Tinder é a maior plataforma de namoro e a mais popular de todas no globo. É de extrema simplicidade na navegação, usando-se apenas os toques para esquerda e direita e está disponível tanto no sistema operacional Android quanto no iOS. Além disso, o aplicativo fornece com frequência versões atualizadas que melhoram o acesso dos usuários, apresentando raramente dificuldades de navegação.

O intuito deste artigo é apresentar como as masculinidades hegemônicas perpassam os selfies no Tinder evidenciando que ao longo da história e em distintos processos culminaram em masculinidades, agora, visíveis no ciberespaço. A ideia de que a masculinidade esteve sempre ligada à morte e a uma versão domesticada, um modelo de arquétipo de pai, guerreiro e provedor do lar permeou construções sociais que até hoje criam estereótipos de toda ordem e que são percebidas em imagens no aplicativo. Essas percepções estiveram presentes na configuração de uma identidade masculina ativa, no excesso sexual, sempre ligados ao código de honra tradicional masculino que apresentava tais valores como transcendentes.

A masculinidade agora é visível, como em outros marcadores sociais (idade, geração, classe, orientação sexual, etc.). Estilos de masculinidades, ou, múltiplas masculinidades se sucedem na vida de um indivíduo ou na vida em sociedade e se relacionam como: masculinidades hegemônicas, masculinidades subalternas, novas masculinidades, masculinidades femininas, masculinidades tóxicas etc. O que vale dizer é que as identidades masculinas não são construídas apenas em relação de oposição ou complementaridade ou ainda simetria às identidades femininas, mas sobretudo à outras identidades masculinas, que, por sua vez também são múltiplas.

\section{Crise e fragmentação das masculinidades}

Parece irônico dizer que as ciências do homem não tinham como objeto de reflexão as masculinidades, ou seja, que esta é uma discussão recente, inclusive no plano das Ciências Sociais. Essa emergência contemporânea das masculinidades e dos homens como objeto de reflexão pode ser lida como sinal mais evidente de um momento limiar do próprio poder masculino. A crítica feminista apontou à exaustão a representação do homem enquanto espécie universal. Não se tratava de uma identidade de gênero em relação à outra, mas, num certo sentido, a identidade masculina englobava a identidade feminina e a representava, tanto 
do ponto de vista político -era o marido que representava a mulher, até o século XX elas não votavam- quanto do ponto de vista cultural. Na própria definição da espécie humana, designada como homo sapiens, ou seja, o homem sempre foi um sujeito universal, ele representava e englobava o feminino. Oficialmente, no século XVII, o masculino individualiza e caracteriza a espécie, a humanidade (Heilborn \& Carrara, 1998).

É a partir da década de 1970 que os primeiros trabalhos sobre masculinidade despontam e os questionamentos sobre as normatizações do ser masculino mostram as contradições a que se submete o homem. Atrelado aos estudos feministas e a sociedade patriarcal, os estudos sobre masculinidades partem de duas vertentes distintas, a primeira ligada à masculinidade hegemônica, material, e a segunda mais contemporânea, pós-estruturalista, em que os referenciais de identidade e subjetividades são o centro dos questionamentos (Heilborn \& Carrara, 1998). Trabalhos pioneiros sobre masculinidades surgem como The Liberated Man (Farrell, 1975 [2013]), The male machine (Feigen-Fasteau, 1974), The forty-nine percent majority (David \& Brannon,1976), Men and masculinity (Pleck \& Swayer, 1974), Men and masculinities: a social, cultural and historical encyclopedia (Kimmel \& Aronson, 2003) apresentando visões panorâmicas da vida dos homens a partir de um enquadramento que aceitou a crítica feminista dos tratados tradicionais de gênero. Os efeitos sociais da divisão de gênero não escapam dos encargos da própria dominação masculina, e o que Bourdieu (1998) propõe é uma tarefa bastante difícil, a mudança de habitus de gênero. Na medida em que a violência simbólica funciona, as mulheres compartilham o mesmo habitus que as oprime.

Para tanto, o conceito de "masculinidade hegemônica" ajuda a determinar como certos grupos de homens exercem versões dominantes da masculinidade ocupando e sustentando relações de poder pela legitimação e reprodução social. Esses relacionamentos geram domínio sobre outras formas de masculinidades e são encarnados por heróis populares, modelos, personagens fictícios apresentados em sagas, filmes, livros, televisão e eventos esportivos. Assim, "a masculinidade hegemônica contém dentro dela a imagem do homem no poder, um homem com poder e um homem de poder" (Kimmel, 1998, p. 58). Desta forma, é cabível ser dito que a masculinidade hegemônica não é um tipo de personalidade ou um personagem masculino, pelo contrário, é um ideal ou um conjunto de normas sociais prescritivas, simbolicamente representadas, uma parte crucial da textura de muitas atividades rotineiras e está, como dito anteriormente, atrelada ao ser racional, bem-sucedido, controlador de emoções e longe de atributos femininos. É enfatizado para eles a coragem, a agressividade, domínio, habilidade tecnológica, aventura entre outras características.

A partir dos anos de 1990, o interesse pelos estudos em masculinidades aumenta drasticamente e um corpo crescente na literatura teoriza uma variedade de tópicos incluindo a violência masculina, a paternidade, a pornografia, as masculinidades femininas e as feminilidades masculinas, estes estudos não 
deixam de ser interdisciplinares e perpassam áreas da Comunicação, Sociologia, Antropologia, Psicologia, Economia, Consumo, dentre outras.

Como pensa Scott (1995), as transformações da tecnologia de reprodução de gênero podem se dar tanto em instâncias biológicas -como os estudos da neurociência ao separar cérebros masculinos e femininos- quanto nas instâncias culturais, seriam tais instâncias que, num futuro próximo, podem eliminar a necessidade dos corpos como agentes de reprodução de estereótipos. $\mathrm{O}$ conceito binário de gênero, segundo Butler (2003), é uma criação performática do sistema patriarcal vigente. Portanto, o gênero está intrinsecamente relacionado aos modos como o homem ou a mulher devem agir, evidenciando assim o binarismo sexista. Para entendermos a questão da identidade de gênero, Butler (2003) ressalta que ele não tem nada a ver com o órgão reprodutor e muito menos com a ordem dos cromossomos, ou seja, identidade de gênero diz respeito a como a pessoa se identifica, a variedade de gêneros é múltipla e não se limita a uma ordem binária. Podemos pensar num corpo masculino que é definido mediante a relação que ele próprio estabelece com a tecnologia, como no caso dos selfies masculinos no Tinder. A noção de corpo é também essencial para a compreensão da imagem na contemporaneidade, visto que o corpo é o espaço de negociação entre o simbólico e o técnico. Assumimos a perspectiva de que a imagem na contemporaneidade representa uma dinâmica triádica entre imagem mental (símbolos e representações), imagem técnica (fotos, vídeos) e o corpo.

A ideia do corpo é fundamental para compreendermos essa nova visualidade que se instaura a partir dos dispositivos digitais aliados a uma rede global baseada na produção do indivíduo. Essa nova visualidade, vem reintegrar o corpo, o sujeito e suas produções simbólica e material num só ente capaz de produzir sentido nas redes sociais. O selfie como objeto visual é um grande promotor dessa nova visualidade, pois nele se confunde significante (objeto), a imagem técnica (suporte) e o próprio corpo (atravessado por uma rede complexa de representações). Uma visualidade na qual o corpo se torna uma tela no qual nos vemos e projetamos uma dimensão de nossa subjetividade. O selfie orienta os usuários a reconhecer sua autoimagem em multiplicidades de situações de modo a que esse olhar do outro que vai consumir sua autoimagem possa revelar signos de sua própria identidade através de comentários, likes e outras manifestações emocionais. Torna-se emblemática essa cultura visual na qual o selfie correlaciona a autoimagem com seu consumo, o corpo se torna tema frequente nessas selfies, sendo, em muitos casos, o corpo no sentido de vitalidade (em academias de ginástica), performático (em coreografias, danças e esforço físico), ou no sentido de corpo sensualizado (com destaque a cenários sensuais ou de cunho sexual). 


\section{A transmidiação do aplicativo Tinder na etnografia multissituada}

Quando um aplicativo como o Tinder integra, já em 2012, um ambiente de comunicação online saturado por outras mídias, foi o algoritmo simples e de fácil combinação que conseguiu ajustar o interesse das pessoas ao se relacionarem afetivamente no ciberespaço pela proximidade geográfica. O Tinder se desenvolve pela narrativa transmídia que converge em múltiplos canais, tanto pela cultura audiovisual quanto pela cultura letrada, contribuindo para o universo das emoções online. A multiplicidade com que o Tinder aparece em diversos meios contribui para o fortalecimento e experimentação desse aplicativo. São universos ricos de histórias, problematizações e revelações que partem de episódios de TV, vídeos curtos no Youtube e histórias narradas em livros e nos perfis das redes sociais. Com esses processos delineados pela transmidiação que acontece pelo smartphone, múltiplas relações convergem entre os usuários e seus afetos.

Ao olharmos para as práticas masculinas que cercam o Tinder, percebem-se os selfies como construção de si partindo dos elementos que se ligam entre o sujeito (correspondente) e o corpo. Buscamos então uma escolha metodológica que possa refletir a importância dos diferentes espaços e tempos que estão presentes no âmbito local -de quem acessa o Tinder pelo smartphone e tem alcance geográfico de $160 \mathrm{~km}$ - e a forma como os correspondentes se apresentam através dos selfies e dialogam em diversas plataformas para além do Tinder.

Optou-se, dessa forma, não só olhar para o aplicativo e os selfies masculinos de modo estanque, mas sim repletos de dimensões e mediações globais que são construídos pelos selfies como apresentação de si no Tinder permitindo visualizar contextos sociais, corporalidades e traços de uma masculinidade hegemônica. A referência teórico-metodológica da etnografia multissituada, inspirada em George Marcus (2001), serve como eixo orientador desta investigação. A etnografia multissituada serve de base para conhecer as várias conexões que se realizam em múltiplos espaços, pois o que ocorre são processos interligados nas redes, nas práticas, nas conexões, nas postagens e nas mediações.

Entender a dinâmica do Tinder como um fenômeno social supõe seguir empiricamente as linhas entrelaçadas que o compõem, mas que transbordam de maneira ampla o perímetro local, justamente porque fazem o traço das redes sobrepostas, de escalas variadas e que atravessam e definem cada situação (Strathern, 2014). A realização da etnografia multissituada não se restringe apenas à prática de campo, engloba o fazer, a forma de relatar e analisar os dados. Trata-se de um olhar sobre determinadas plataformas digitais que permitem a construção de um fenômeno que dialoga e se liga às práticas dos correspondentes: os selfies masculinos. E é nessa prática de recomposição de múltiplas perspectivas e situações que as configurações se moldam para que o fenômeno das masculinidades hegemônicas ganhe sentido. A proposta de uma etnografia multissituada é o desafio de estudar novas culturas online, conexões, paralelos 
e contrastes entre uma variedade de plataformas midiáticas e aplicativos e uma emergente condição de pesquisa nos campos interdisciplinares como o feminismo, as masculinidades, os estudos pós-coloniais e culturais como tradições da própria antropologia e da comunicação.

As múltiplas localidades investigadas a partir do aplicativo Tinder requerem estratégias para delinear "uma arquitetura contextual" (relacional, social e pessoal) que são entregues pelos sujeitos em seus perfis públicos. Desta maneira, uma "etnografia móvel toma trajetórias inesperadas" (Marcus, 2001, p. 112), percebemos que, para além do uso do Tinder, novas plataformas e redes sociais são acionadas (Facebook, Instagram, WhatsApp) e acabam por contribuir com novas conexões e associações de sujeitos em diversas localidades no ciberespaço. Ao fazer o recorte empírico da pesquisa apenas com homens, nossa busca foi para a amplitude máxima da geolocalização do aplicativo de $160 \mathrm{~km}$ e para as idades de 18 a 55 anos. Em um primeiro momento, a relação com os usuários era receber os matches correspondidos para iniciar os diálogos. Ao refletirmos sobre a investigação e a relação com os correspondentes, foi possível selecionar dez homens com quem mantivemos contato desde então, alguns apenas pelo Tinder, outros pelas redes sociais Facebook e Instagram e ainda WhatsApp. Desta forma, a seleção da pesquisa se deu através da análise dos selfies masculinos no Tinder. O perfil da pesquisa no Tinder ficou aberto para homens de 18 a 55 e a distância máxima de alcance do aplicativo de $160 \mathrm{~km}$. Assim, ao dar match em todos os perfis, tivemos 590 correspondências até março de 2017.

Elementos da masculinidade hegemônica como a virilidade e a atividade sexual foram os primeiros momentos das entrevistas pelo Tinder, quando os correspondentes faziam valorização do corpo viril, pois essa valorização está representada nos selfies com os corpos malhados em academias, como mostraremos a seguir. No Tinder, a masculinidade hegemônica pode significar ter encontro com várias mulheres e dominá-las, mas a busca por namoradas e sexo casual também é frequente. Das correspondências, apenas um caso de infidelidade conjugal foi revelado. Ao todo tivemos $590^{1}$ correspondências.

\section{Deu match! Os selfies como masculinidade hegemônica}

Podemos constatar que os correspondentes atravessam diferentes campos sociais, mas mantêm entre si uma cumplicidade estrutural: uma masculinidade

1 Dos 18 aos 24 anos podemos encontrar: Estudante; Vendedor; Autônomo; DJs; Maratonista; Piloto; Garoto de programa. Dos 25 aos 30 anos temos: Eng. Civil; Professor; Consultor de viagens; Personal Trainer; Eng. Computação; Advogado; Engenheiro; Corretor; Servidor público; Construtor; Projetista; MBA gestão empresarial; Médico; Competidor MMA; Vendedor; Publicitário; Aux. Contábil; Cineasta; Músico; Dono de restaurante; Radialista; Designer; Eng. Agrônomo; Soldado militar; Dono de academia. Correspondentes dos 31 aos 40 anos: Jornalista; Publicitário; Advogado; Médico; Representante Comercial; Vendedor; Frentista; Mecânico; Filósofo; Design; Fotógrafo; Diretor de televisão; Músico; Agricultor. E dos 41 anos aos 55 encontram-se: Aposentado; Advogado; Servidor público; Pedreiro; Policial; Militar; Bombeiro. 
hegemônica ativa e presente nos selfies apresentados nos perfis, consolidando o interesse heteronormativo socialmente dominante no aplicativo. Essa materialização não é meramente reproduzida ou, ainda, reflexiva, ela requer condições materiais e simbólicas, mas também depende, como indica Bourdieu (1998), diretamente do grau de autonomia relativa do campo social e do objeto em disputa a partir dos quais ele procede, tamanha é a relevância estrutural do Tinder para a recriação das relações de dominação e reprodução de gênero. Tais disputas simbólicas exprimem, inclusive, nas práticas profissionais, na escolha do vestuário um reconhecimento do homem viril e autêntico, pronto para a dominação feminina, e é o que veremos a seguir.

\section{Imagem 1. Homens usando terno no Tinder}

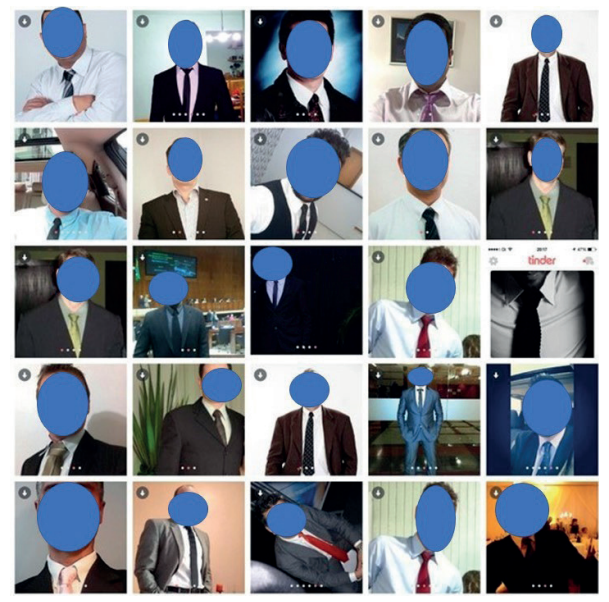

Fonte: Reprodução Tinder (2015; 2016).

O campo sempre nos mostra algo que até então parecia "escondido" do nosso olhar. Um aspecto no vestuário dos correspondentes chamou nossa atenção enquanto navegávamos pelos perfis no Tinder. Conforme Simão e Mesquita (2010), para além da exposição de um corpo sarado, os homens de terno eram tão presentes e constantes quanto os sem camisas. Os ternos masculinos, geralmente na cor preta, refletem uma posição social. Para John Harvey (2004), o terno preto emite poder, bens e autoridade, numa representação que vai além das aparências, refletindo as relações entre os homens na sociedade, pois, para o autor, "é evidente que as roupas significam alguma coisa, e prova disso é a dificuldade em imaginar uma roupa que não tenha significado algum" (Harvey, 2004, pg. 38). Para Simão e Mesquita (2010), o terno assume um valor simbólico, e a materialidade dos signos que envolvem o objeto passa a ter certa importância na afirmação de um vestuário clássico e atemporal. Assim, a publicização dos selfies de terno partindo do vestuário num ambiente de hiperconexão, onde 
a experiência individual está a todo tempo sendo reportada à rede, no sentido de Latour (2008), de fluxos, circulações, alianças, movimentos, que não se posicionam com fixidez num ponto, mas sendo fluído, inconstante e escorregadio. Pensamos também o selfie como um ator não-humano, em conformidade com a teoria do ator-rede de Bruno Latour (2008), agente promotor de uma nova visualidade e que integra as demais visualidades ao permitir que os agentes humanos promovam formações imaginárias, representações e criem modalidades de si através de imagens técnicas.

Assim, o vestuário assume um papel de importância, oferecendo expressão de estilo às identidades masculinas. Embora o custo de um bom terno não seja de acesso às camadas populares, acredita-se que essa peça do vestuário masculino "restringiu seu uso a uma estreita gama de profissionais de classe média alta, como as áreas de direito, administração e finanças” (Crane, 2006, p. 34,2). Além de tudo, o homem que veste o terno transmite competência, articulação e comprometimento com o mercado industrializado, o consumo e as normas sociais. Para os autores acima, o terno constitui a roupa mais masculina que já se viu e está baseada em estética e versatilidade capazes de trazer anonimato a quem o veste. Sobre a permanência desta peça ao longo dos anos e ainda continuar super atual, o terno se tornou um código masculino do vestir sempre vinculado ao poder, à capacidade intelectual, à seriedade e ao profissionalismo (Simão \& Mesquita, 2010).

Ao observarmos a relação dos correspondentes com a moda, compreende-se uma técnica corporal "definida e colocada em prática em virtude das especificidades culturais da sociedade, valorizando certos comportamentos em detrimento de outros" (Crane, 2006, p. 371). Os papeis de gênero no que toca ao vestuário podem acentuar ou atenuar certos tipos de masculinidades pela estética não verbal, mas veiculada pelo vestuário. Se o terno é popular nos selfies masculinos no Tinder, outro estilo também chamou atenção. Homens com camisa xadrez, barba espessa no estilo "lenhador" americano.

Imagem 2. Homens no estilo lenhador no Tinder
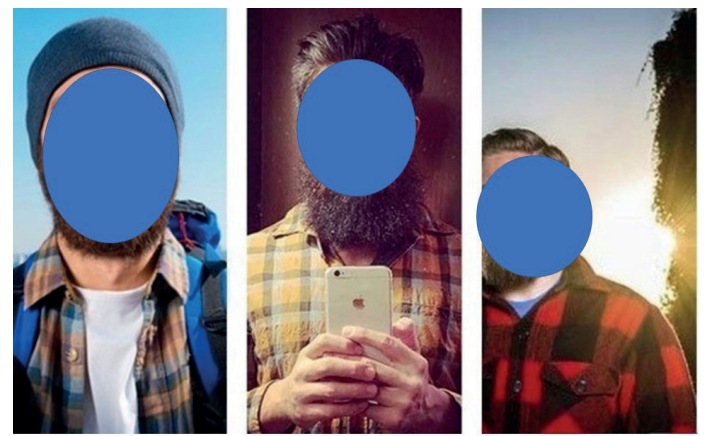

Fonte: Reprodução do Tinder (2016/2017) 
Ao passar uma imagem de virilidade, Lucas (23 anos) confessa que faz sucesso entre as mulheres. Segundo o correspondente, esse estilo mostra que o homem "tem uma pegada mais forte do que os mauricinhos", ou seja, para ele é mais aceito e tem maior repercussão do que aqueles que se arrumam demais, os chamados metrossexuais. O despojado do vestuário com jeans surrado e botas "é a imagem do homem de verdade" (Lucas, 23 anos). Para os correspondentes do Tinder, essa tendência é o resultado de uma sociedade em que o homem pode exercer maior liberdade estética sem perder a masculinidade. Mas esse traço do estilo masculino "lenhador" está próximo do que os autores (Kupers, 2005; Robles, Peretz \& Kohli, 2016) chamam de masculinidade tóxica. O significado mais profundo deste contexto é que os homens têm que estar prontos para lutar. Certamente não significa que um homem deve se envolver em qualquer briga de bar. Há muitas interpretações do conceito de "masculinidade tóxica", mas aqui a entendemos como a capacidade do homem para operar sem falhas, sem medo e confiar em seu próprio conhecimento, "pois um homem real nunca irá se comportar de forma impotente" (André, 24 anos).

A toxic masculinity se baseia em competir com os outros homens e outras mulheres e dominá-los, sendo uma tendência problemática dos homens. Essas tendências masculinas promovem a resistência à dor, à sensibilidade e à psicoterapia e se apresentam geralmente sob a forma de estresse e complexidades da vida do homem moderno. A relação entre masculinidade hegemônica e masculinidade tóxica integra dinâmicas individuais e institucionais que intensificam a masculinidade tóxica, ocasionando, muitas vezes, obstáculos estruturais ao tratamento de saúde mental. Geralmente a masculinidade tóxica está atrelada à violência e agressão como um ideal cultural da própria masculinidade onde a força é tudo, e onde, como consequência, acidentes e até mortes acontecem. Entendemos que os estudos de gênero difundidos pelo mundo desenvolveram sua própria linguagem sobre a evolução das normas sociais e crenças relacionadas às masculinidades hegemônicas. Em certo sentido, este processo foi determinante para mudanças fundamentais que têm afetado toda sociedade no âmbito da produção, do consumo, da organização do trabalho e do lazer relacionado aos homens.

No aplicativo Tinder, a masculinidade hegemônica se manifesta como um homem, um ser social, no mundo material através de um corpo, emoções e razões, traz consigo uma virilidade exposta que é um potencial divulgador de sua força. Para Jeolás e Kordes (2010), um dos significados de atribuir risco + masculinidade é o que chamamos de racha de carros e motos. Desta forma, as autoras questionam "se a busca da velocidade e da aceleração pode ser pensada como uma metáfora para os percursos de vida fluídos, flexíveis e incertos" (Jeolás \& Kordes, 2010, p. 3), próprios do contexto da "sobremodernidade" a partir dos jovens que se apropriam dos veículos para testar seus limites. 
Imagem 3. Homens nos veículos fazendo selfie

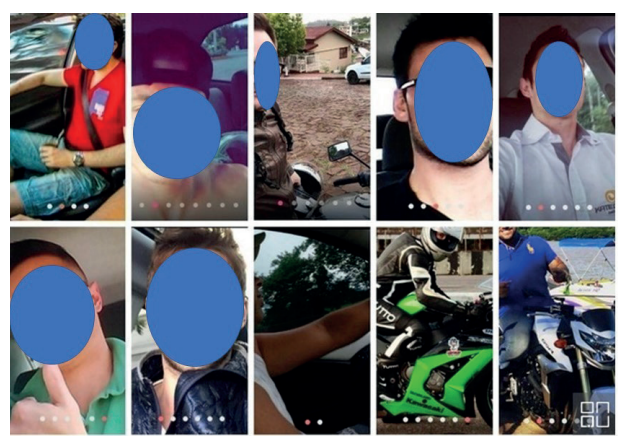

Fonte: Reprodução Tinder (2015/2016).

Há uma bricolagem nos veículos, como colocam as autoras, que também servem como ritos de passagens para estes homens jovens que não estão preparados para ingressar numa sociedade que impõe limites e regras, assim, os rachas marcam uma passagem e um status com comprovação pública de "alguns dos valores centrais ao modelo de masculinidade hegemônico tradicional, como a coragem e a competitividade" (Jeolás \& Kordes, 2010, p. 07). A maioria dos correspondentes tem selfies dentro dos carros e atribuem ao veículo força e virilidade. Para Felipe (33 anos) e João (32 anos), o carro representa um cartão de visitas para a mulher, e o controle do carro aparece como uma extensão da identidade masculina. Desta maneira, a exposição em selfies encarna este potencial, isto é, busca desenvolver a consciência do que significa ser um homem real, que tem por significado revelar todo seu potencial, ou seja, toda a sua masculinidade. Essas considerações nos remetem ao conceito de potencial, como o único propósito da forma de realização incorporada devido às aspirações para explorar o seu próprio potencial viril e sexual, tanto no salto de paraquedas de Felipe quanto na atividade de mergulho de João.

Imagem 4. Homens fazendo selfie de alto risco
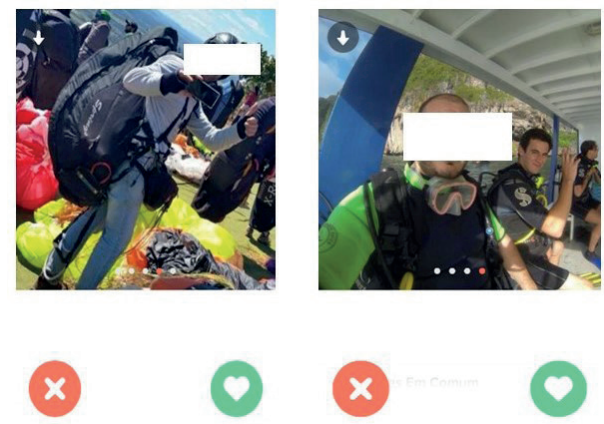

Fonte: Reprodução Tinder (2016/2017). 
Reproduz-se, nos selfies que apresentam o paraquedismo e o mergulho dos correspondentes Pedro (29 anos) e Marcos (37 anos), uma masculinidade atrelada à aventura, flertando com riscos, morte e excessos no estilo aventureiro. Os correspondentes revelaram que, ao longo da vida, têm um medo real do fracasso. Começaram gradualmente, desde cedo, a perceber que são responsáveis por tudo, incluindo a busca pela esposa e construção de uma família, e, não tendo em mãos um guia confiável para a vida, eles chegam à conclusão assustadora: são sozinhos no mundo e precisam se aventurar. Em outras palavras, cabe a eles a busca por uma vida feliz, bem-sucedida e satisfatória. Estes homens estão destinados a achar o caminho, para liderar e assumir a responsabilidade não só pela sua vida, mas também pela vida da mulher. Mas aqui está o problema: eles não sabem como, não há um manual para isso. Não nos esqueçamos de que cada um dos correspondentes absorveu as convenções prevalecentes na sociedade, ditando o que deve ser um homem. Todos foram ensinados a pensar racionalmente, foram ensinados que um homem não deve chorar, e o que é bom é um homem grande, forte e corajoso. Assim, nenhum homem veio ao mundo sabendo se realizar enquanto homem ou como acionar o poder masculino. A perpetuação das masculinidades hegemônicas está configurada de forma que o homem deve, em primeiro lugar, assumir um papel de liderança e, por outro, indicar a direção e, em terceiro lugar, determinar os meios de atingir a meta do sucesso.

Seis correspondentes da pesquisa acreditam que a mulher deve, incondicionalmente, cumprir suas ordens. Assumir a liderança significa iniciar um ato de ação. Não importa se é um ato de conversa, ato de respeito em silêncio, ato de inspiração, ato de assistência ou uma relação sexual. Cada sentimento de liderança envolve necessariamente um ato de iniciação. Para os usuários do Tinder, um homem não pode se dar ao luxo de ser impotente, hesitante e fraco. A masculinidade hegemônica também está atrelada à ideia de o homem ser o detentor de conhecimentos especializados, ou seja, apresentando um poder genuíno, normalmente, percebidos como habilidade, talento ou mesmo genialidade. Os correspondentes João (32 anos), Tiago ( 27 anos) e Tadeu (34 anos) acreditam que, com a evolução dos conhecimentos obtidos ao longo da vida, seus potenciais másculos vêm à tona e se materializam pelas informações assim adquiridas. Segundo Connell (2013), a masculinidade hegemônica é entendida como um padrão de práticas que possibilitaram que a dominação dos homens sobre as mulheres continuasse como um processo normativo social que incorpora a forma mais honrada de ser homem. Para o autor, "os homens que receberam os benefícios do patriarcado sem adotar uma versão forte da dominação masculina podem ser vistos como aqueles que adotaram uma cumplicidade masculina" (Connell, 2013, p. 245).

Se olharmos para as masculinidades hegemônicas, será fácil entender que, para um homem realizar seu pleno potencial, não significa ele se abster de seus prazeres, fazendo coisas que não são voltadas para a manutenção do seu estilo 
de vida. No nível local, padrões de hegemonia da masculinidade estão embutidos em ambientes sociais específicos, tais como as organizações e instituições formais. Assim, muitos não só não desistem da experiência de se abrir, mas também manifestam a autodisciplina para praticar abstinências. No entanto, a fim de mostrar todo o seu potencial no condicionamento social de "machos alfa", permanecem na linha das convenções adotadas na sociedade que perpetua as masculinidades hegemônicas. Tais correspondentes estão muitas vezes dispostos a impressionar, e veem como um sinal de fraqueza o medo de se tornarem vítimas através da manipulação dos níveis mentais ou emocionais. Desta forma, o verdadeiro significado do sucesso do homem reside no fato de que ele deve ser prático se não quiser ficar confuso e se perder em meio ao caos das emoções desconhecidas. A este respeito, recordemos que o único propósito da vida deles, no plano físico, é a divulgação do potencial de toda a sua virilidade.

Ao repensar o conceito de masculinidade hegemônica, Connell (2013) entende que a atribuição do termo permanece dentro de uma lógica de dicotomização do sexo (biológico) x gênero (cultural), desta forma, marginalizando ou naturalizando o corpo masculino. Como foi percebido aqui pelos correspondentes ao longo da pesquisa, esse modelo de masculinidade hegemônica se expressa em várias falas e selfies como um ideal de gênero masculino que se articula com a constituição prática das masculinidades como formas de viver as circunstâncias cotidianas locais e "na medida que fazem isso, contribuem para a hegemonia na ordem de gênero societal” (Connell, 2013, p. 253). Quando falamos sobre a masculinidade tradicional, estamos nos referindo a um conjunto de valores, crenças, atitudes, mitos, estereótipos e comportamentos que legitimam e dotam os homens do poder de exercitá-lo e os leva à crença de que a experiência masculina de sujeito é a medida das experiências humanas. No contexto dos correspondentes do Tinder, a masculinidade hegemônica é, portanto, baseada em uma visão androcêntrica do mundo dentro de um sistema social e cultural patriarcal baseado na ideia de autoridade e liderança masculina. Um sistema em que há predominância de homens sobre mulheres, onde as estruturas de produção e a reprodução do poder estão em grande parte fundamentadas na desigualdade das relações de gênero.

Um dos aspectos observáveis da identidade masculina, nesta pesquisa, indica a insistência em demonstrar continuamente as habilidades dos correspondentes contra a derrota pessoal, em todas as esferas. Este modelo heroico é presente em relação à autoconfiança própria na busca pelo reconhecimento das mulheres. O heroico em nosso artigo apresenta o sentido desenvolvido por Gilbert Durand (2002), como parte do imaginário social alicerçado pelos valores da dominação do outro, dos mitos ascensionais e da separação do homem de seu ambiente. A afirmação dessa masculinidade exige demonstrações contínuas de bravuras, que variam significativamente dependendo da idade. Os correspondentes adotam atitudes que banalizam a segurança e estão baseados em comportamentos de risco demonstrando sua "coragem" como afirmação de sua 
virilidade, como o paraquedismo, o mergulho, o motocross, a doma de cavalos, etc. Esses comportamentos de risco também se baseiam na maneira pela qual, na maior parte, a identidade masculina concebe o corpo como invulnerável. Os homens não só usam seus corpos, mas flertam com a sensação de risco para serem considerados "homens de verdade".

No contexto das masculinidades hegemônicas existe uma grande propensão para arriscar a vida a serviço da afirmação de gênero, trazendo esse elemento subjetivo como a principal característica de identificação do homem forte e corajoso. Acidentes com carros ou motos, a participação em esportes de alto risco, em exércitos e conflitos armados, ou grupos violentos, são algumas práticas extremas que se enquadram no modelo de masculinidade hegemônica.

O modelo hegemônico de masculinidade impõe aos homens uma maneira estereotipada e restrita de atuar no mundo, trazendo consequências negativas para os próprios homens. Esses problemas, que são considerados específicos da masculinidade, uma vez que afetam significativamente os homens, também são uma consequência do sistema de socialização de gênero, e estes se tornam muitas vezes protagonistas do sofrimento. Para Le Breton (2013), a busca pela liberdade e autorreferência pode gerar uma desordem, pois as ações e as decisões dos correspondentes, no que tange ao risco em suas vidas, encara a morte como um endosso de uma masculinidade que testa o valor da vida. A exposição ao risco, para o autor francês, nada mais é do que uma conquista inútil envolvendo limites e riscos desnecessários para o homem que tenta provar sua potência. Ao encontro do pensamento de Le Breton, Cechetto (2005) acredita que a capacidade de resistência à dor e à exposição ao risco de vida é um fator decisivo na construção do valor corporal e da masculinidade.

\section{Considerações finais}

Os correspondentes desta pesquisa e usuários do Tinder estão cada vez mais conectados e presentes no mundo virtual, sendo possível identificar os dispositivos ligados à internet. Eles os carregam diariamente na mochila, na mão, no bolso ou no carro, oferecendo uma série de conveniências, surpreendendo-os com o amor a um toque de distância, por aplicativos cada vez mais sofisticados e de simples utilização, bem como com redes sociais que os unem cada vez mais enquanto indivíduos sociais. Estes usuários compartilham o sentimento do quão habilitados estão em uma era hiperconectada. Os correspondentes desta pesquisa, que são usuários do aplicativo Tinder, revelam dormir com o aparelho, olham para o dispositivo com frequência diariamente, debruçam-se sobre a tela enquanto interagem com amigos, familiares e paqueras.

Alguns correspondentes acreditam que vivemos em uma época de conexão e mobilidade crescente, mas que o individualismo surge a partir da maior oferta de gadgets, e as pessoas acabam se isolando. Mesmo com aplicativos com propostas 
bem definidas, como o Tinder, redes cada vez mais segmentadas se realocam no ciberespaço conforme interesses pessoais e coletivos e criam, assim, novas formas de sociabilidade, laços sociais e interação intencional. Este novo estilo de vida que agrega aparatos tecnológicos em nosso cotidiano tem sido pensado de forma bastante inovadora pelo campo das Ciências Sociais, com destaque para a Cibercultura, a Antropologia Digital e também a Comunicação. Esta pesquisa é uma contribuição para estas áreas que buscam refletir e pensar os atores em diferentes contextos sociais, inseridos no ciberespaço e suas relações de gênero.

O smartphone continua sendo um facilitador para a produção de identidades autênticas e até mesmo para a reprodução de identidades que enfatizam uma desigualdade ou igualdade de gênero. Os smartphones e aplicativos, neste caso, o Tinder, compõe uma realidade que conduz a comportamentos que se entrecruzam na socialização e construção da apresentação de si pelo gênero masculino. No repertório emocional e afetivo atrelado aos selfies masculinos no Tinder, observamos desempenhos de funções específicas e básicas que estão agregadas diante das novas tecnologias, principalmente ao uso e apropriação dos dispositivos móveis.

O prazer sexual e a satisfação em se divertir diariamente pelo Tinder são habitus compartilhados pelos dez correspondentes. Assim, os selfies simbolizam uma realidade que, para o outro, torna-se metáfora para a emoção, neste caso, os registros imagéticos masculinos no Tinder seriam atemporais, sem causa nem efeito, pois tudo é possível de ser representado e reproduzido. Os selfies masculinos no Tinder também seguem uma lógica emocional com suas próprias regras, sendo definidas pelas identidades masculinas (hegemônicas ou não) e de como elas são percebidas.

O estudo das masculinidades é relativamente novo, assim como o estudo sobre os smartphones. Mas, no campo das masculinidades hegemônicas, o Brasil desponta como um país ainda embrionário no que tange a estes estudos. Inovador também são os estudos sobre o que podemos chamar de novas masculinidades ou este novo homem no ciberespaço e seus discursos que prezam pela igualdade de gênero. Avaliamos que a estética do selfie se torna promotor de uma visualidade calcada na relação individual, presentificada e corporificada num sistema integrador de informação e de comunicação (as redes sociais) com fins de criar ações de marketing e de vigilância a partir de metadados sobre um conjunto de usuários, organizados por algoritmos. A imagem se corporifica através da estética do selfie e ganha múltiplas possibilidades de uso pelo capital.

Por fim, acreditamos que conseguimos nos distanciar do pensamento reproduzido de que os indivíduos que tiram selfies são narcisistas unicamente. Observamos que, na construção do selfie veiculado nas mídias sociais, neste caso o Tinder, os indivíduos agregam aspectos psicológicos, sociológicos, identitários que não se restringem apenas à imagem de si, mas são capazes de incorporar o mundo que os cerca e os constitui, como uma história a ser contada. 


\section{Referências bibliográficas}

Bourdieu, P. (1998). A dominação masculina. Rio de Janeiro: Bertrand Brasil.

Butler, J. (2003). Problemas de gênero: feminismo e subversão da identidade. Rio de Janeiro: Civilização Brasileira.

Cechetto, F. R. (2005). Violência e estilos de masculinidade. São Paulo: FVG Editora.

Connell, R. (2013). Masculinidade hegemônica: repensando o conceito. Florianópolis: Revista Estudos Feministas.

Crane, D. (2006). A moda e seu papel social - classe, gênero e identidade nas roupas. São Paulo: SENAC.

David, D. \& Brannon, R. (1976). The Forty-nine Percent Majority: The Male Sex Role. New York: New York Penguin Books.

Durand, G. (2002). Estruturas antropológicas do imaginário. São Paulo: Martins Fontes.

Farrell, W. (2013 [1974]). The liberated man: Freeing men and their relationships with women. New York: Random House.

Feigen-Fasteau, M. (1974). The male machine. New York: Mac Graw-Hill.

Harvey, J. (2004). Homens de Preto. São Paulo: UNESP.

Jeolás, L. \& Kordes, H. (2010). Percursos acelerados de jovens condutores ilegais: o risco entre vida e morte, entre jogo e rito. Porto Alegre: Horizontes Antropológicos.

Heilborn, M. L. \& Carrara, S. (1998). Dossiê Masculinidade. Em cena, os homens... Revista Estudos Feministas, 6(2), 270-421.

Kimmel, M. (1998). The gender of desire: essays on masculinity. USA: New York Press.

Kimmel, M. \& Aronson, A. (2003). Men and masculinities: a social, cultural and historical encyclopedia. New York: The New York Public.

Kupers, T. A. (2005). Toxic masculinity as a barrier to mental health treatment in prison. Journal of Clinical Psychology, 61(6), 713-724.

Latour, B. (2008). Reensamblar lo social: una introducción a la teoria del actor-red. Buenos Aires: Manantial.

Le Breton, D. (2013). Adeus ao corpo: Antropologia e sociedade. Campinas: Papirus.

Marcus, G. E. (2001). Etnografía en/del sistema mundo - el surgimiento de la etnografía multilocal. México DF: Alteridades.

Pleck, J. H., \& Sawyer, J. (Eds.). (1974). Men and masculinity. Prentice Hall.

Robles, E.; Peretz, A. \& Kohli, S. (2016). Fear of the other and toxic masculinity in the age of Trump. Berkeley: Haas Institute.

Scott, J. (1995). Gênero: uma categoria útil de análise histórica. Educação \& Realidade, 20(2), 71-99.

Simão, L. de A. \& Mesquita, C. (2010). O terno: questões e reflexões. São Paulo: Design, Arte, Moda e Tecnologia.

Strathern, M. (2014). O efeito etnográfico. São Paulo: CosacNaify. 